\title{
Entre liberdade individual e saúde coletiva: saberes e práticas em caso de descontinuidade do tratamento da tuberculose
}

\author{
Between Individual Freedom and Collective Health: Knowledge and \\ Practice in the Event of Discontinuity of the Treatment of Tuberculosis
}

Francisca Souza Santos Dias

Instituto Federal do Norte de Minas Gerais. Brasil

ID ORCID: https://orcid.org/0000-0002-0898-8565

E-mail: francisca_souzasantos@yahoo.com.br

Márcia Grisotti

Universidade Federal de Santa Catarina, Brasil

ID ORCID: https://orcid.org/0000-0003-0389-7100

E-mail: marcia.grisotti@ufsc.br

Recepción: 13.08.2019

Aprobación: 14.12.2019

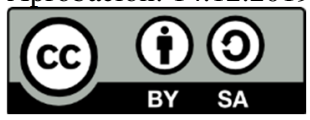

Resumo: A tuberculose permanece causando sofrimento humano e morte em pleno século XXI, representando um relevante problema de saúde pública. $\mathrm{O}$ artigo analisa os conflitos entre a liberdade individual e a saúde pública relacionados ao tratamento da tuberculose e como eles são percebidos e gerenciados pelos profissionais e contatos envolvidos no processo. Trata-se de uma pesquisa qualitativa, na qual entrevistas semi-estruturadas foram realizadas com os contatos dos portadores de tuberculose, bem como, com os profissionais de saúde da Vigilância Epidemiológica e da Estratégia Saúde da Família, envolvidos no Controle da Tuberculose no município de Araçuaí - MG. Na análise dos dados verificou-se a tensão entre a liberdade individual e a saúde pública, evidenciando que a descontinuidade do tratamento se relaciona com os dois sentidos políticos de liberdade. Enquanto no sentido negativo a pessoa é considerada livre quando nenhuma pessoa ou grupo interfere em suas ações, no sentido positivo, a liberdade é compreendida como a autodeterminação do indivíduo. Portanto, considerando os riscos que a liberdade na decisão por não aderir ao tratamento (sentido positivo) pode acarretar para a coletividade, a concepção de liberdade negativa aplicada pelo sistema de saúde brasileiro está baseada na interferência, exigindo condutas e estratégias diante desses casos.

Palavras-chave: tuberculose, liberdade individual, tratamento, saúde pública, risco. 


\begin{abstract}
Tuberculosis remains a significant cause of human suffering and death in the twenty-first century and represents a relevant public health problem. The article analyzes how the conflict between individual freedom and public health is related to tuberculosis treatment and how they are perceived and managed by the professionals and contacts involved in the process. This is qualitative research, in which semi-structured interviews were conducted with contacts of tuberculosis patients, as well as health professionals from the Epidemiological Surveillance and Family Health Strategy, involved in Tuberculosis Control in the city of Araçuaí, MG.The data analysis verifies the tension between individual freedom and public health, showing that the discontinuity of treatment is related to two political senses of freedom. While in the negative sense the person is considered free when no person or group interferes with his actions, in the positive sense freedom is understood as the self-determination of the individual. Therefore, considering the risks that freedom in the decision not to adhere to treatment (positive sense) may bring to the community, the conception of negative freedom applied by the Brazilian health system is based on interference, requiring conduct and strategies in these cases.
\end{abstract}

Keywords: tuberculosis, individual freedom, treatment, public health, risk.

\title{
INTRODUÇÃO
}

O crescimento desordenado das cidades vem sendo atualmente tema de grandes discussões, tendo em vista que conforme Soares, Alencar, Cavalcante e Alencar (2014) o processo de urbanização na maioria das vezes não está acompanhado de planejamento, com ocupação em áreas insalubres sujeitas a condições de risco, além de doenças e epidemias causadas pela falta higiene e serviços sanitários. Todas essas condições de transformação urbana resultam em modificações no perfil de morbidade, com o surgimento de novas doenças e o reaparecimento de outras, principalmente as de origem infecciosa, algumas das quais eram consideradas erradicadas e outras, controladas.

Neste contexto, encontra-se a tuberculose, que mesmo sendo uma das doenças mais estudadas nos seus aspectos biológico, epidemiológico, clínico, terapêutico e profilático, permanece causando sofrimento humano e morte em pleno século XXI, representando um relevante problema de saúde pública no cenário mundial.

O governo brasileiro reconhece a tuberculose como uma doença de profundas raízes sociais, relacionada à pobreza e à má distribuição de renda, cenário este que justifica o grande número de casos de tuberculose em municípios como Araçuaí, localizado no Estado de Minas Gerais. No ano de 2013, foram notificados dezenove casos de tuberculose nesse município, sendo quinze casos novos, três recidivas e um caso de reingresso após descontinuidade, todos os casos são de tuberculose pulmonar. Além disso, o maior número de pessoas com tuberculose reside na zona urbana do município (DATASUS, 2014). 
No campo da saúde pública, a tuberculose é reconhecida como prioridade entre as políticas governamentais, sendo o tratamento oferecido exclusivamente pelo SUS (Sistema único de Saúde). No entanto, mesmo com a disponibilização gratuita da medicação, observa-se que muitos pacientes interrompem o tratamento e só retornam após o reaparecimento dos sintomas. Esta decisão pelo não tratamento da tuberculose pode ser analisada sob várias óticas. Uma delas, remete à concepção "negativa" da liberdade em que a pessoa é considerada livre na medida em que nenhum homem ou grupo interfere em sua atividade, com a preservação de uma esfera individual de autonomia (Berlin, 2002).

Todavia, é preciso considerar que além das implicações para o indivíduo, a descontinuidade do tratamento de uma doença infecciosa também traz implicações para o coletivo, com a colisão entre dois direitos fundamentais: o direito à liberdade individual e o direito à saúde coletiva. Desta forma, o modelo liberal da política transfere para a lei a normatividade das ações humanas, com limites da liberdade individual, proteção dos direitos e definição do alcance do poder político (Ramos, 2011).

Este estudo se justifica pela escassa literatura que analisa os impasses na aplicação de políticas públicas nos casos onde existe uma relação ambígua, e aparentemente contraditória, entre o respeito das singularidades do indivíduo, possibilitando que o mesmo seja sujeito ativo no processo saúde-doença e as sérias repercussões epidemiológicas, por exemplo, decorrentes da descontinuidade ou recusa do tratamento da tuberculose. De acordo com o Instituto de Pesquisa Econômica Aplicada - IPEA (2011), além de poder ocasionar o desenvolvimento da tuberculose resistente aos medicamentos, favorece que o sujeito seja transmissor da doença, tendo em vista que os doentes não tratados são potencialmente transmissores, implicando na garantia de saúde para a população.

O preceito constitucional da saúde como um direito universal, garantido pela Constituição brasileira, embora reconhecido como um avanço social é, também, desde o final da segunda metade dos anos 1990, a base para o crescimento exponencial do número de mandatos judiciais na saúde que, em sua maioria, buscam garantir o acesso das pessoas a medicamentos, procedimentos diagnósticos e terapêuticos. Neste sentido, o cidadão se voltaria ao Judiciário como estratégia de mobilização de recursos e argumentos para a defesa e conquista de direitos (Asensi, 2010).

No entanto, partindo da análise das relações entre políticas de saúde universais e subjetividade, direitos individuais e direitos coletivos, controle e liberdade individual, esta pesquisa aborda a judicialização da saúde no sentido de garantir 
os direitos coletivos à saúde. Considerando que o Ministério Público tem sido o agente mais importante da defesa de direitos coletivos pela via judicial e, dado que os conflitos relativos a tais direitos têm geralmente conotação política.

Surge, então, a seguinte indagação: Quais são os saberes e práticas em relação ao tratamento ininterrupto por 180 dias para o tratamento da tuberculose pulmonar e como os conflitos são gerenciados pelos profissionais e/ou especialistas que estão envolvidos no processo?

\section{MATÉRIAS E MÉTODOS}

Trata-se de uma pesquisa qualitativa que permite captar elementos da cultura, valores, atitudes e comportamentos das pessoas que se pretende analisar. Para o delineamento desta pesquisa, optou-se pelo estudo de caso que tem por objetivo explorar um caso singular, situado na vida real contemporânea, delimitado e contextualizado em tempo e lugar para realizar um levantamento apurado de informações (Chizzotti, 2006).

O cenário da pesquisa foi o município de Araçuaí - MG, localizado no Vale do Jequitinhonha. O Vale do Jequitinhonha, composto por 80 municípios, é uma região que ocupa 14,5\% da área do Estado de Minas Gerais, totalizando aproximadamente $85.000 \mathrm{Km} 2$ de extensão territorial, está situado geograficamente na região nordeste do estado, fazendo fronteiras com o Norte de Minas Gerais e o Mucuri (Nascimento, 2009).

Conforme o Departamento de Informática do Sistema Único de Saúde [DATASUS] (2014), na última década, a região Sudeste concentrou o maior número de casos de tuberculose, sendo que somente no estado de Minas Gerais, foram notificados 4.094 casos. Segundo estimativa do Instituto Brasileiro de Geografia e Estatística [IBGE] (2013), em 2013, Araçuaí ocupava o $3^{\circ}$ lugar em relação à maior população do Vale do Jequitinhonha.

A escolha desse cenário de estudo ocorreu pela elevada prevalência dos casos de tuberculose pulmonar neste município, acima da média da região, destacando-se em número de casos dentre os municípios com população similar que compõem o Vale do Jequitinhonha. Enquanto em Araçuaí que possui 37.169 habitantes, foram notificados dezenove casos de tuberculose, em Diamantina com 47.647 habitantes, foi notificado apenas um caso, em Almenara que possui 40.749 habitantes foram notificados dez casos, Capelinha com 36.740 habitantes foram notificados três casos, Itamarandiba com 33.804 habitantes, também foram notificados três casos (DATASUS, 2014). 
Além disso, ressalta-se que a tuberculose está intrinsecamente relacionada a um conjunto de fatores tais como as precárias condições de vida da população, na medida em que tende a se disseminar em populações mais pobres, residentes em aglomerados urbanos e carentes de serviços elementares de saúde.

Relacionando esses fatores com a realidade do município, observa-se que em Araçuaí há um contraste entre a riqueza da produção agrícola, da riqueza mineral e artística e a carência de oportunidades para os trabalhadores/as do município. Há, portanto, ausência de políticas públicas que contribuam com o desenvolvimento da cidade, agregando valores nas riquezas naturais da região e possibilitando ampliar o seu mercado comercial (Santos, 2012).

Os participantes desta investigação foram seis profissionais que atuam na vigilância epidemiológica do município e na Estratégia Saúde da Família e por fim, oito contatos de pessoas que tiveram tuberculose no ano de 2013. Os contatos entrevistados possuem relação direta com os portadores de tuberculose (Tabela 1).

TABELA 1: PERFIL dos CONTATOS PARTICIPANTES DA PESQUISA

\begin{tabular}{l|l|l}
\hline Identificação & Grau de Parentesco & Profissão \\
\hline C1 & Neta & Secretária \\
\hline C2 & Mãe & Do lar \\
\hline C3 & Vizinha & Do lar \\
\hline C4 & Mãe & Do lar \\
\hline C5 & Filho & Servente de pedreiro \\
\hline C6 & Mãe & Do lar \\
\hline C7 & Filha & Do lar \\
\hline C8 & Mãe & Do lar \\
\hline
\end{tabular}

Fonte: Elaboração própria.

Quanto aos profissionais de saúde, foram entrevistadas duas enfermeiras, duas técnicas de enfermagem e duas agentes comunitários de saúde (Tabela 2).

Através da solicitação de autorização à Secretaria Municipal de Saúde do município de Araçuaí, obtivemos permissão para a coleta dos dados. Após reunião com a enfermeira, coordenadora da vigilância epidemiológica, tivemos acesso aos prontuários e registros dos contatos dos pacientes que tiveram tuberculose. Os profissionais de saúde foram convidados a participar da pesquisa. O material coletado foi interpretado com base na análise dos saberes e práticas em relação ao tratamento da tuberculose dos participantes da pesquisa. 
TABELA 2: PERFIL DOS PROFISSIONAIS PARTICIPANTES DA PESQUISA

\begin{tabular}{l|l|l}
\hline Identificação & Profissão & Tempo de trabalho \\
\hline EN01 & Enfermeira & 1 ano \\
\hline TE01 & Técnica em Enfermagem & 1 ano \\
\hline EN02 & Enfermeira & 4 anos \\
\hline ACS01 & Agente Comunitária de Saúde & 1 ano \\
\hline TE02 & Técnica em Enfermagem & 20 anos \\
\hline ACS02 & Agente Comunitária de Saúde & 1 ano \\
\hline
\end{tabular}

Fonte: Elaboração própria.

A investigação foi encaminhada ao Comitê de Ética e aprovada sob o número do parecer: 842.608 e o consentimento dos participantes foi formalizado por meio da assinatura do Termo de Consentimento Livre e Esclarecido - TCLE. Para manter o anonimato dos participantes no registro dos resultados da pesquisa, os contatos das pessoas com tuberculose foram identificados no texto pela letra $\mathrm{C}$ seguida de um número sequencial de realização da entrevista (C1 a C8); e os profissionais de saúde foram identificados no texto segundo a profissão, sendo os enfermeiros identificados em EN01 e EN02, os técnicos em enfermagem por TE01 e TE02 e os agentes comunitários de saúde por ACS01 e ACS02.

$\mathrm{O}$ instrumento utilizado para coleta de dados foi a entrevista semiestruturada. As vantagens dessa entrevista, apontadas por Gil (1999: 118), residem no fato deste instrumento oferecer maior flexibilidade, visto que o entrevistador pode esclarecer o significado das perguntas; possibilitar a obtenção de dados referentes aos mais diversos aspectos da vida social e ser muito eficiente para a obtenção de informações em profundidade sobre o comportamento humano. $\mathrm{O}$ que possibilita a entrevista ser um instrumento privilegiado para coleta de informações. Num primeiro momento, foi realizado um pré-teste do roteiro da entrevista, visando à adequação aos objetivos propostos. Segundo Marconi e Lakatos (2003), a análise dos dados obtidos no pré-teste permite evidenciar possíveis falhas existentes, a complexidade das questões, ambiguidades ou linguagem inacessível, permitindo evidenciar perguntas supérfluas ou que causem embaraço ao informante.

$\mathrm{Na}$ etapa de pré-análise, as entrevistas foram transcritas na íntegra, e efetuada a leitura flutuante para tomar conhecimento do material produ- 
zido e poder avaliá-lo quanto à pertinência dos conteúdos e homogeneidade dos discursos.

$\mathrm{Na}$ etapa de exploração do material transcrito, identificaram-se as unidades de registro, fez-se a classificação que consistiu em analisar essas informações para relacionar as que tinham características comuns e agrupá-las de acordo com as questões presentes na informação, fez-se a reorganização temática, gerando as categorias e os temas.

Na etapa dos resultados, buscou-se a identificação dos saberes e práticas dos profissionais de saúde e dos contatos dos portadores de tuberculose em relação à descontinuidade do tratamento da tuberculose, procurando compreendê-los e interpretá-los à luz do referencial teórico.

\section{A TUBERCULOSE TEM HISTÓRIA: VIVÊNCIAS DO ADOECER E DO TRATAMENTO}

No ano de 2013, foram notificados dezenove casos de tuberculose no município de Araçuaí. Sendo que quinze foram casos novos, três recidivas e um caso de reingresso após a interrupção do tratamento. O único caso de reingresso após interrupção do tratamento é de um participante deste estudo que foi identificado com o nome fictício de José. Além de ser portador de tuberculose, ele é contato de outras pessoas que também possuem a doença. Ele tem trinta e oito anos, é natural de Araçuaí, solteiro, servente de pedreiro. Há mais de dois anos, foi diagnosticado com tuberculose pulmonar. Quando adoeceu, estava trabalhando fora da cidade e acredita que adquiriu a tuberculose a partir de uma complicação da pneumonia.

Que no caso eu trabalhava fora, né. Eu senti aquela pneumonia. Eu acho que foi da pneumonia que eu a peguei. Eu também mexo com muita poeira, com essas coisas, né. Ajuda, prejudica um pouco. (C5)

José mora em uma casa simples, em uma rua sem calçamento e sem rede de esgoto, na periferia da cidade. Um fato instigante ocorreu ao chegar para entrevistá-lo. Apesar das recomendações da agente comunitária de saúde - de manter a casa sempre arejada pelo risco de transmissão da tuberculose - José estava dentro de casa com sua mãe, com as portas e janelas fechadas. A entrevista foi gravada na sala de sua residência, na qual mora com dois filhos, sua mãe, o pai e dois sobrinhos.

José realizou o tratamento por três vezes. Em fevereiro de 2014 reiniciou o tratamento, sendo realizado o teste de sensibilidade e constatado 
resistência à isoniazida, medicamento do esquema básico. O processo da resistência aos medicamentos na tuberculose é grave para os pacientes que receberam tratamento anterior sem sucesso. Muitas vezes, as lesões avançam por recidivas e tratamentos insuficientes, favorecendo o aparecimento de bacilos resistentes a uma ou mais drogas (Rastogi, David, 1993).

Tanto o esquema especial quanto o esquema básico trazem prejuízos ao paciente, a ingestão diária de comprimidos, efeitos adversos da medicação, dores no local da aplicação da injeção, entre outros. A tuberculose, sendo uma doença crônica e debilitante, necessita de um tempo prolongado de tratamento e pode representar para o doente um empecilho em sua atuação no trabalho. A doença implica em modificações importantes no cotidiano do indivíduo (Vendramini, Villa, Palha, Monroe, 2002).

Eu parei porque eu estava trabalhando e tinha hora que não dava pra eu pode ir, né. Eu peguei e parei. (C5)

José retornou ao tratamento após o ressurgimento dos sintomas, incluindo tosse persistente e emagrecimento. Para Oliveira e Moreira Filho (2000), o reingresso do paciente com tuberculose pode ocorrer após ter interrompido o tratamento previamente, estar reiniciando ou completando esquema terapêutico, ou já ter realizado tratamento anterior, recebido alta por cura e estar retornando por recidiva da doença.

Mas já tinha acabado, completado. Aí voltou de novo. Agora eu tomei dois meses de injeção e o resto de comprimidos. Foram 60 injeções e 840 comprimidos. (C5)

O tratamento da tuberculose, durante 180 dias ininterruptos, traz exigências aos pacientes que muitas vezes não são percebidas pelos profissionais. Assim, o paciente mantém em suas lembranças a quantidade de comprimidos e o ônus do tratamento, tendo em vista que o tratamento muitas vezes não vem acompanhado do sucesso. José mostra-se inconformado, pois mesmo seguindo o tratamento, é acometido novamente pela tuberculose.

Agora eu desanimei porque voltou de novo. Não sei por quê. Porque eu tomei os medicamentos. Eu fiz tudo certinho. (C5)

Esse relato evidencia um sentimento de decepção, na medida em que mesmo buscando seguir a prescrição médica, o organismo pode voltar a ser acometido por esta doença, como é o caso deste entrevistado.

O caso de José reflete a situação de muitas famílias em que há mais de uma pessoa com tuberculose na mesma casa, pois além dele, um dos filhos e a sua mãe 
possuem tuberculose. Situação em que o portador de tuberculose antes de seguir o tratamento ou após recusa deste, transmite aos seus contatos esta doença.

Os depoimentos de José aqui apresentados, a respeito da singularidade do caso, revelam a forma como é percebida e como desenvolveu a doença em sua vida. A rotina da ingestão de medicamentos, a tosse persistente, o emagrecimento, o abandono do serviço, a luta contra o alcoolismo.

Para que sejam analisados os conflitos em relação à convivência e ao tratamento da Tuberculose sob a perspectiva da liberdade de escolha do indivíduo, torna-se necessário dar voz aos sujeitos envolvidos, no intuito de compreender os saberes e práticas daqueles que convivem com o portador de tuberculose, ressaltando suas experiências e o significado da doença. Assim, nesta pesquisa foram entrevistadas a mãe e uma vizinha de José, sendo a última, a única vizinha que sabe que ele é portador de tuberculose. Os outros contatos não foram entrevistados por serem crianças e o pai de José não estava disponível para a entrevista.

Por ser um evento que ameaça ou modifica a vida individual, a inserção social e, por conseguinte, o equilíbrio coletivo, a doença concebe sempre uma necessidade de discurso, a necessidade de uma interpretação complexa e contínua. "O sujeito, sua experiência, o sentido que ele mesmo dá à sua ação tornou-se objeto de estudo de máxima legitimidade" (Herzlich, 2005: 64).

Segundo Alves e Rabelo (1999), a experiência da doença é entendida como a "forma pela qual os indivíduos situam-se perante ou assumem a situação de doença, conferindo-lhe significados e desenvolvendo modos rotineiros de lidar com a situação" (Alve, Rabelo, 1999:171). Eles apontam ainda que, "as respostas aos problemas criados pela doença constituem-se socialmente e remetem diretamente a um mundo compartilhado de práticas, crenças e valores" (Alves, Rabelo, 1999: 171).

Assim, para que se possa compreender a vivência com a tuberculose, tornase necessário conhecer como essa doença é percebida tanto pelo portador da tuberculose quanto pelas pessoas que convivem com o mesmo.

A tuberculose tem que ser uma doença vista especialmente porque é grave, pode levar ao óbito se não ocorrer o tratamento certo. E tem que ter todo um procedimento. Ajudar a pessoa que tiver com o agravo. É isso, bem por aí. (C1)

As pessoas têm medo, se afastam pelo fato de que quando a pessoa tem a doença, ele não vai chegar para você e falar. (C3)

A tuberculose é uma doença muito forte, atacada. Eu mesmo quando adoeci estava pesando 80 quilos, aí como eu fiquei sem apetite pra comer, eu fui emagrecendo, emagrecendo, com dor no peito, sabe? Aquela falta de apetite, aquela dor assim, no peito, eu acho que era de fraqueza, né, porque não estava comendo. Fazia um soro pra tomar, estava passando mais era com soro. Aquele soro que eu tomava já satisfazia. Eu fui emagrecendo, emagrecendo, ema- 
grecendo, aí foi indo que eu não estava aguentando mais. Estava dando umas dores, essa dor assim, da morte. Dói muito. Muita dor, muito forte. Tossia. Depois que eu tomei os remédios, que acabou o tratamento, eu ainda tusso. (C7)

A análise das entrevistas evidenciou que a tuberculose é percebida pelos sintomas que apresenta. $\mathrm{O}$ emagrecimento constante é um dos sinais que mais chama a atenção dos participantes, estando associado à perda de apetite, cansaço, falta de ânimo. A febre e a tosse incontrolável acompanhada das dores passam a serem sintomas que requerem investigação.

Febre, muita febre. Dava uma febre grande demais, era uma febre atrás da outra. A febre roendo por dentro. Porque a febre não saía, era só por dentro. É isso que é a tuberculose. Você começou tossir, você pode saber que é ela. (C2)

Tossindo e eu achando que era gripe. Não fui ao médico não. Quando eu fui ao médico eu já tava ruim já. (C5)

O tratamento é assumido pelo contato quando adquire a doença como garantia da cura, uma necessidade imperiosa, sem alternativa, evidenciando a sua submissão a uma situação que somente a terapêutica é capaz de mudar (Vendramini, Villa, Palha, Monroe, 2002). Para os contatos, seguir o tratamento conforme orientado pelo profissional de saúde é quase sempre uma tarefa difícil e não se resume em apenas aceitar sua prescrição. Os doentes expressam dificuldades, mas as consideram imprescindíveis para a cura.

Como eu disse é importante, porque tem casos que não quer se tratar e acaba transmitindo pra outras pessoas. Então tem que ter o tratamento. (C1)

É bom. Chega certinho. Eu tomava até no PSF. (C5)

A presença de pessoas que possam partilhar com o doente, tanto o enfrentamento da enfermidade quanto os obstáculos relacionados ao tratamento medicamentoso, tornam-se um fator importante e decisivo para adesão ao tratamento (Vendramini, Villa, Palha, Monroe, 2002). Os contatos relataram a experiência de cuidar de um familiar com tuberculose.

Ele ficou doente, ficou doente. Zé você está com problema de pulmão e Zé: "Eu não estou não". É pulmão, vamos tratar? Aí eu insisti com ele, fui insistindo, até que ele foi comigo. Aí ele foi devagarzinho, sentava, levantava, sentava, levantava, até que nós chegamos ao hospital. Aí quando nós chegamos lá, entramos pra consultar, eu entrei com ele e contei o médico o caso. Ele falou assim: "Vamos ver se é isso mesmo. Vamos fazer uma chapa". Fez a chapa e deu nos dois. Tava com problema de pulmão. Aí vamos passar os remédios pra ele. Eu fui ao posto, peguei os remédios pra ele para sessenta dias. Eram cinco remédios. Ai esses remédios eu trouxe para dá-lo. Fui dando os remédios pra ele, fui dando para ele o leite, bife de fígado mal passado. Só coisa forte, ovo quente, fui dando, com dois meses o homem nem parecia que estava doente. $\mathrm{C} 2$

A assistência ao portador de tuberculose é marcada por situações em que o paciente inicia e posteriormente interrompe o tratamento, ou outras em que completa 
o esquema e tem alta por cura sem intercorrências, mas também são frequentes os casos também em que há a dificuldade em aceitar o processo de adoecimento. Situações em que os profissionais de saúde lidam com a pessoa que não reconhece que é portador de tuberculose, como evidenciado na fala.

Porque como eu disse, nem todo mundo às vezes acredita que tem essa doença. Meu avô principalmente foi assim. $\mathrm{C} 1$

Além das influências das condições de vida da população na incidência da tuberculose, verifica-se que a baixa escolaridade, indicador importante de nível econômico, é um importante fator que influencia no abandono ao tratamento da tuberculose. Essa relação é estabelecida, tendo em vista que o paciente com nível escolar baixo muitas vezes não consegue compreender as informações ou o profissional instruir o paciente de maneira menos formal e não esclarecendo dúvidas, direcionando ao desinteresse e consequentemente a não aderência (Júnior, Santos, Gibaut, Bispo, 2016).

A tuberculose é uma doença diretamente associada às condições do meio e que desencadeia graves problemas sociais e para a saúde pública, tendo em vista que acomete principalmente indivíduos em idade produtiva e desfavorecidas social e economicamente. Para Ruffino-Netto (1991), no processo de produção e reprodução dentro das classes sociais as condições de vida são desiguais, ocasionando diversas possibilidades de encontros nos quais poderá acontecer a transmissão da tuberculose.

Geralmente, as pessoas acometidas possuem baixa renda familiar, educação e habitação precárias, famílias grandes, desnutrição, alcoolismo, residem em agrupamentos comunitários, doenças infecciosas associadas e difícil acesso aos serviços de saúde, demonstrando que as ações de controle não se limitam apenas ao setor da saúde (Larroque, Santos, 2015). No entanto, a visão do profissional de saúde, muitas vezes, encontra-se alicerçada na perspectiva eminente biológica, em detrimento da compreensão social do processo saúde-doença, observando-se um atendimento fragmentado e setorizado, desvalorizando as relações do indivíduo com o meio.

Os profissionais de saúde muitas vezes não compreendem a vivência subjetiva dos doentes e seus familiares e as dificuldades do tratamento, bem como, a liberdade de escolha em não se tratar diante das exigências do tratamento para o doente. Conforme Reiners, Azevedo, Vieira e Arruda (2008), os profissionais abordam o processo saúde-doença apenas sob suas perspectivas, ignorando as do paciente. 
Nesse sentido, a recusa do tratamento pode ser vista de diversas formas, como falta de responsabilidade ou compromisso do paciente, mas também pode ser entendida como uma liberdade de escolha baseada em múltiplas justificativas da pessoa em querer ou não se tratar. No entanto, enquanto a recusa do tratamento para doenças não infecciosas implica em riscos apenas individuais, a recusa do tratamento da tuberculose traz consequências mais amplas, considerando que a tuberculose pulmonar é uma doença transmissível por via aérea e a pessoa quando não adere ao tratamento pode transmiti-la a seus contatos, colocando em risco a saúde dos outros.

\section{TUBERCULOSE PULMONAR: OS LIMITES DA LIBERDADE INDIVIDUAL E AS ESTRATÉGIAS DA SAÚdE PÚBLICA}

Ao longo da história, os maiores problemas de saúde que as pessoas enfrentaram sempre estiveram relacionados com a natureza da vida em comunidade. Melhorias no ambiente, na provisão de água e alimentos apropriados para consumo, na assistência médica foram medidas de saúde pública que possibilitaram o controle das doenças transmissíveis (Rosen, 1994).

Segundo estimativas da Organização Mundial da Saúde (OMS), em 2015, ocorreram 10,4 milhões de novos casos de tuberculose no mundo que causaram a morte de 1,8 milhão de indivíduos. No Brasil, a tuberculose é a terceira maior responsável pelos óbitos por doenças infecciosas e a primeira entre pacientes com AIDS no país (Ministério da Saúde, 2012).

Vários estudos revelam que mesmo com a disponibilização do tratamento pelo SUS, o risco de descontinuidade do tratamento da tuberculose é elevado ao final do primeiro mês e no início do segundo, ou em um tempo inferior a cinco meses. De acordo com a OMS, isso se deve ao desaparecimento dos sintomas, nos primeiros dias da medicação, e pela duração do esquema tradicional que é de seis meses (IPEA, 2011).

Considerando que a tuberculose é uma doença transmissível por via aérea, a pessoa quando não adere ao tratamento pode transmiti-la a seus contatos, colocando em risco a saúde do outro. Nesse contexto, é possível evidenciar um conflito entre o direito individual à liberdade e o direito coletivo à saúde. Ressalta-se que um dos deveres do Estado consiste em impedir a invasão dos direitos produzida pela interferência indevida dos cidadãos e, sobretudo, do próprio poder político, sendo cumprido por meio da lei sobre todos igualmente (Ramos, 2011). 
Do ponto de vista teórico, estamos lidando com um dos problemas centrais da modernidade, marcada pelo pacto securitário com o predomínio da segurança em detrimento de práticas de liberdade e singularidades. Essa tensão, coloca em destaque as ambivalências do processo civilizatório: o não reconhecimento das contingências, complexidades e insolubilidade de certos problemas da vida impulsionam a tentativa de abolir todos os sofrimentos (impossível), o qual acaba produzindo sofrimentos ainda maiores e fazendo com que a civilização avance de modo cego no sentido de mais segurança.

Para analisar os limites da liberdade individual e a tendência da modernidade em colocar a segurança como uma necessidade (mesmo que isso implique no sacrifício de outros ideais que também valorizamos), é imprescindível resgatar a contribuição de Hobbes (1961) quanto à efetivação do Estado por meio do contrato social. O autor, parte da premissa de um Estado de Natureza, no qual a liberdade dos indivíduos não encontra nenhum obstáculo, podendo ser utilizada da maneira que mais lhe convir para preservação de sua vida, uma situação em que se encontra uma constante disposição para a disputa. Sobre essa condição, Hobbes denomina de condição de guerra, pois enquanto não foi instituído um poder suficientemente grande para a segurança, cada um confiou apenas em sua própria força e capacidade (Lopes, 2012). Nesse sentido, os indivíduos, movidos pelo medo, pela 'insegurança total' e por uma 'guerra de todos contra todos', estabelecem um contrato, trocando a sua liberdade individual por segurança e a liberdade natural que existia no Estado de Natureza torna-se liberdade civil (que é a base da concepção liberal de segurança).

A criação do Estado e seus dispositivos, representam o meio para se conseguir a paz, e através disso a própria conservação dos indivíduos, O soberano surge com o contrato feito entre os súditos, que aceitam limitar suas liberdades e transferi-las a uma pessoa ou assembleia, em troca de paz e segurança (Lopes, 2012).

A discussão liberal sobre a liberdade avança no sentido de precisar o âmbito e a extensão da liberdade individual, bem como as possibilidades do seu constrangimento mediante a lei. Benjamin Constant desenvolveu um texto (1819), no qual apresenta uma distinção entre o que denomina a liberdade dos antigos e liberdade dos modernos. Para os antigos, a liberdade consistiria em ser quase sempre soberano nas questões públicas e escravo em todos seus assuntos privados. Já para os modernos, a liberdade seria um meio para a segurança privada.

Já no século XX, a discussão sobre a liberdade foi equacionada, de modo exemplar, pelas análises de Isaiah Berlin, no ensaio "Dois Conceitos de Liberdade". Neste ensaio, o autor propõe examinar os dois sentidos políticos de liber- 
dade, o negativo e o positivo. No primeiro sentido a pessoa é considerada livre na medida em que nenhuma pessoa ou grupo interfere em suas ações. Por essa razão, a liberdade passa a ser chamada de negativa, isto é, ela existe na ausência de ações que podem criar impedimentos arbitrários e indevidos à livre atividade dos sujeitos, enquanto que no sentido positivo, a liberdade é compreendida como a capacidade de autodeterminação do indivíduo, por meio da autonomia da vontade. Ela é positiva, porque a liberdade significa o desejo de o indivíduo ser senhor de si próprio e da sua atividade (Berlin, 2002).

No que se refere à relação da liberdade com a lei, Berlin entende que a lei consiste em uma notória interferência externa na área em que o indivíduo pode agir livremente conforme o mesmo considerar apropriado. Por mais legítima que seja a lei, resultará sempre em diminuição da liberdade individual (Silva, 2008). No entanto, Berlin afirma que, até certo limite, isso pode ser justo e mesmo necessário, pois a elaboração de leis que limitam a liberdade em benefício de outros bens seria um recurso justificável. (Silva, 2008).

Foucault também abordou a possibilidade de práticas da liberdade a partir de uma relação refletida de resistência aos campos de saber e de poder, tratando de pensar a liberdade como uma prática possível no interior dos sistemas formados por estes campos (Ribas, 2017). Delineando, dessa forma, a noção de população, como sendo de uma maneira geral, aquela que resiste a regulação.

Não obstante da simetria aparente, o próprio sujeito coletivo (população) é muito diferente do sujeito coletivo constituído e criado pelo contrato social, ao considerar que a população aparece como uma realidade muito mais densa do que um agrupamento de súditos submetidos ao soberano. E, com isso, vai ser preciso que o Estado assuma essa nova realidade. Neste sentido, o Estado tem sob sua responsabilidade uma sociedade civil, devendo assegurar a sua gestão (Foucault, 2008a: 470).

A saúde e o bem-estar físico da população, em geral, surgem como um dos objetivos essenciais do poder político. A doença, como fato de grupo e de população, é problematizada, a partir de instâncias em relação às quais o Estado desempenha papéis diversos, com a emergência em pontos múltiplos do corpo social, da saúde e da doença, como problemas que exigem, de uma maneira ou de outra um encargo coletivo, sendo a saúde de todos como urgência para todos; o estado de saúde de uma população como objetivo geral (Foucault, 2013: 298). Nesse processo, Foucault (2013: 430), descreve a era da governamentalidade que, segundo ele, foi o fenômeno que permitiu ao Estado sobreviver, sendo ao mesmo tempo exterior e interior ao mesmo. As estratégias de governo permitem definir 
a cada momento, o que deve ou não incumbir ao Estado, o público ou privado, o que é ou não estatal. Portanto, o Estado deve ser compreendido com base nas técnicas gerais da governamentalidade.

A tuberculose, mesmo sendo uma enfermidade antiga, persiste como problema sério de saúde pública que necessita de ações urgentes, especialmente porque seu tratamento é permeado por situações em que o paciente não realiza o tratamento corretamente ou o abandona antes do término, acarretando, assim, aumento no número de casos, redução nas taxas de cura, o aparecimento de tuberculose multirresistente e elevadas taxas de óbito (Vendramini, 2001).

A não-adesão dos pacientes com tuberculose à terapêutica oferecida, representa um dos principais problemas encontrados pelo Programa de Controle da Tuberculose, em que os pacientes tornam-se crônicos tanto da doença quanto da utilização dos serviços. A adesão transcende o ato de ingerir o medicamento e se relaciona diretamente ao lugar ocupado pelo indivíduo no processo de produção e reprodução social, na medida em que desse decorrem condições favoráveis ou limitantes para a efetivação da manutenção terapêutica. Além disso, a adesão refere-se às concepções de saúde-doença que apresentam os indivíduos portadores da enfermidade, assim como, aos aspectos que dizem respeito à organização dos serviços de saúde (Bertolozzi, 1998).

Neste sentido, a adesão ao tratamento da tuberculose pode ser vista como a liberdade de escolha de um sujeito ativo no processo saúde-doença em aceitar ou não as propostas terapêuticas impostas pelo Programa de Controle da Tuberculose. No entanto, essa liberdade de escolha em não se tratar de uma doença transmissível, pode trazer implicações para a saúde da população.

$\mathrm{O}$ direito à liberdade, se tornou um elemento necessário para a própria governamentalidade; somente governa-se bem se efetivamente, a liberdade ou determinadas formas de liberdade forem respeitadas. Tendo em vista que o não respeito a liberdade, não é somente exercer violações de direito em relação à lei, mas não saber governar como se deve. A integração das liberdades e de seus limites próprios, dentro da prática governamental, tornou-se imprescindível (Foucault, 2008a: 475).

Com o governo da população, não se observa mais o surgimento de um poder que adotaria a forma de uma vigilância exaustiva dos indivíduos, mas o conjunto de estratégias que tornam-se pertinentes para o governo e para os que governam, fenômenos bem específicos que não são precisamente os fenômenos individuais (Foucault, 2008a: 87). 
A biopolítica lida com a população como problema a um só tempo científico, político, biológico e como problema de poder (Foucault, 2005). A governamentalidade, sustentada na normalização biopolítica, tem em programas incidentes sobre a saúde das pessoas um modo de governo da vida das populações. Nesses espaços, a conduta de cada sujeito é normatizada e conduzida com fins políticos. No entanto, ainda que seja o governo quem coloca o sujeito envolto no corpo social, o poder exige uma margem de liberdade para o seu exercício.

Para Foucault, existem apenas práticas de liberdade que não corresponde à liberdade irrestrita de um sujeito que se denomine e se constitua enquanto livre, mas, a um conjunto de práticas possíveis dentro dos condicionantes sociais, nos quais há os outros sujeitos e os valores, em que a liberdade individual tem um papel importante (Lopes, 2012).

A prática de liberdade diz respeito ao modo com que o sujeito se relaciona com a sujeição, aceitando-a ou resistindo. Nesse sentido, destaca-se a descontinuidade do tratamento da tuberculose que representa uma resistência a uma norma e uma ruptura com a estratégia proposta para a sua cura. Tendo em vista que a tuberculose, encontra-se permeada por estratégias biopolíticas para minimizar os riscos de adoecimento da população, sendo que essa doença não é individual, mas sim social, que se propaga por via aérea aos outros membros da sociedade, muitas vezes sem o seu conhecimento e consentimento, curável, desde que diagnosticada e tratada corretamente (Sbarbaro, 1997).

\section{GERENCIANDO OS CONFLITOS RELACIONADOS À CONVIVÊNCIA} E AO TRATAMENTO

A saúde pública é uma ampla área para a investigação das relações de poder e da maneira pela qual o Estado é constituído e compreendido. Com a instituição do Sistema Único de Saúde, essa discussão torna-se ainda mais abrangente, tendo em vista que propõe a universalização dos serviços desde as ações de saúde coletiva até a atenção de alta complexidade. Progressivamente, a política nacional de saúde foi se constituindo em uma rede de instituições, com concepção das doenças transmissíveis como um problema político (Pessoto, Ribeiro, Guimarães, 2015).

No Brasil, em caso de descontinuidade do tratamento de tuberculose, o Estado estabelece a hierarquização das ações de saúde com a distribuição das competências pelas três esferas da administração pública que são: a federal, a estadual e a municipal. Sendo que estas correspondem, respectivamente, ao Ministério da Saúde, as Secretarias Estaduais de Saúde e as Secretarias Municipais de Saúde. 
A partir dessa divisão, essas esferas organizam-se de acordo com a complexidade exigida pelas diferentes formas de organização administrativa, política e/ou geográfica (Ministério da Saúde, 2011).

A primeira medida, quando o profissional verifica que o paciente interrompeu o tratamento, é a busca ativa que consiste em uma visita domiciliar para verificar por quais motivos o paciente não buscou a medicação ou procurou o serviço de saúde pública. Assim, a visita domiciliar no controle da tuberculose possui três funções. A primeira é a função tática que é penetrar na intimidade do tecido social para detectar precocemente; a outra é a função de representação que significa reforçar a ordem médica e a autoridade sanitária. E por último, a função de controle, para verificar o cumprimento das normas sanitárias de profilaxia da tuberculose (Barreira, 1992).

Visando reduzir as altas taxas de interrupção do tratamento e suas implicações para a saúde pública, o controle de contatos é outra atividade constante após o diagnóstico da tuberculose ou em caso de descontinuidade de tratamento, sendo prioritariamente indicado para as pessoas que convivam com doentes bacilíferos, especialmente os intradomiciliares, e nos adultos que convivam com doentes menores de cinco anos para identificação da possível fonte de infecção.

Outra estratégia aplicada é o Tratamento Diretamente Observado de Curta Duração (DOTS) que contribui para o aumento da adesão dos doentes ao tratamento, pois significa ter a certeza que o doente realmente ingeriu os medicamentos, mas é preciso ressaltar que essa supervisão pode representar uma ideia que retoma o passado autoritário do sanitarismo (Perini, 1998). Como observado na fala do profissional:

Foram uns dois meses nós administrando a dose supervisionada, todos os dias oral e intramuscular. A gente não entregou para ele a medicação, foram dois meses assim, no final de semana e no feriado também. (EN01)

Essa estratégia de tratamento se aproxima do que era vivido pelos doentes do sanatório que, submetidos ao isolamento, não tinham como esconder que eram tuberculosos. Da mesma forma, a presença constante dos profissionais de saúde na casa do paciente pode dificultar o ocultamento da informação social diante da vizinhança (Silva, 2009).

Em alguns estudos, foi verificado que para os profissionais, a DOTS se refere a ver, controlar e observar a ingestão da medicação. Uma estratégia que torna possível interromper a cadeia de transmissão, obter a cura, além de impedir eventos indesejáveis do tratamento incorreto, acompanhar os contatos, abordar dificuldades inerentes ao tratamento, diminuir a resistência dos bacilos aos medica- 
mentos e organizar o serviço de saúde (Terra, Bertolozzi, 2014). No entanto, a DOTS tem sido apontada como mecanismo de desconstrução da autonomia do sujeito doente ou infantilização do mesmo (Campos, 2003), por não possibilitar que o indivíduo se responsabilize pelo tratamento e decida como este pode ser realizado, ficando essa atribuição para a equipe de saúde.

Além disso, a DOTS pode acentuar não somente a crença na periculosidade da doença como na periculosidade do próprio doente que necessita de vigilância na administração do seu próprio corpo. Isso porque o tratamento supervisionado requer vigilância e controle obstinados que muito se assemelham ao tratamento empregado na era sanatorial. A exigência de comparecer à unidade de saúde e o questionamento dos agentes comunitários de saúde sobre como o doente administra não somente a medicação, mas a sua vida, configura uma abordagem capaz de trazer à memória antigas representações (Silva, 2009).

Os profissionais, ao prestarem assistência ao paciente, sentem-se corresponsáveis pelo processo de recuperação e cura deles e, por vezes, utilizam diversas estratégias para que o paciente prossiga com o tratamento, como se pode verificar na fala de um dos profissionais entrevistados: "Os dois são fundamentais. O papel e a responsabilidade são dos dois". (EN02)

Conforme o Programa de Controle da Tuberculose, a hospitalização é indicada somente em algumas situações especiais, com o período de internação reduzido ao mínimo necessário (Ministério da Saúde, 2011). No entanto, atualmente, essas internações são muito menos indicadas pela gravidade dos sintomas do que pelas condições psicossociais do doente em conduzir seu tratamento. Frequentemente, os casos que merecem internação são considerados os "casos sociais", como os moradores de rua e dependentes químicos, ou seja, aqueles que não apresentam condições psicológicas ou socioeconômicas de realizar o tratamento em sua própria residência, necessitando de vigilância mais apurada (Silva, 2009).

Para os pacientes com interrupção de tratamento persistente, em que seja considerado que o mesmo esteja colocando em risco a saúde da população, medidas judiciais podem ser adotadas como a internação compulsória. De acordo com Fujiwara, Larkin e Frieden (1997), o Código de Saúde da Cidade de Nova York dizia que todos os pacientes com tuberculose ou suspeita deveriam ser examinados; completar tratamento; aderir a um programa de tratamento supervisionado (ou CoDOT, quando administrado por um agente de justiça); ser detidos, durante o período de transmissibilidade ou até a cura, e quando outras alternativas de tratamento não obtiverem sucesso. Hoje existem leis que preveem a internação 
compulsória em todos os cinquenta Estados americanos devido aos elevados percentuais de descontinuidade de tratamento.

No Brasil, a internação compulsória é indicada após realizadas todas as medidas para adesão do paciente. Considerando os riscos da tuberculose para a população e para o próprio doente, segundo o manual de recomendações, a descontinuidade de tratamento deve envolver profissionais de saúde, inclusive da saúde mental, a sociedade civil, os profissionais do Judiciário e outros setores do Governo, justificando porque interrupções sucessivas e/ou recusas reiteradas em submeter-se aos tratamentos preconizados podem levar ao desenvolvimento de bacilos extensivamente resistentes (Ministério da Saúde, 2011). Os dilemas na adoção dessas diretrizes se evidenciam na fala de um profissional entrevistado:

E quando se esgota todas as possibilidades. Esgotar possibilidades significa recorrer comunidade, família, amigos, serviços de saúde, postos referenciais nesse amparo. Para que a gente possa estender essa situação de conscientização de que o doente precisa ser tratado. Com todas as possibilidades esgotadas a gente recorre ao poder público, à polícia, às vezes a gente tem até indícios, nada cientificamente, que teria que a polícia teria que fazer parte da equipe. O que nós já fizemos enquanto município é recorrer ao ministério público. Conversamos com o promotor do município por casos que já ocorreram aqui de abandono e que isso estava comprometendo uma série de situações até mesmo crianças. Então a gente já recorreu à promotoria, já recorremos a juízes do município. E aí a gente foi abrindo espaços, entrelinhas para a gente trabalhar com as situações. (EN02)

Observa-se neste cenário uma pluralidade de instituições e atores que atuam na construção e garantia de direitos à saúde da população. Portanto, o Judiciário se apresenta como mais um desses atores, em que suas competências e atribuições constitucionais concernem, principalmente, à resolução de conflitos (Asensi, 2010).

No contexto brasileiro, o Ministério Público (MP) recebeu destaque enquanto instituição jurídica envolvida no processo de efetivação da saúde enquanto direito. No geral, o MP desenvolve a capacidade institucional de criar um espaço de comunicação entre os principais envolvidos que compõem o processo de elaboração, gestão e fiscalização das políticas públicas em saúde (Asensi, 2010).

A positivação do direito à saúde como um direito fundamental na Constituição de 1988 enseja avanços e novos desafios jurídicos, culturais, políticos, sociais e econômicos para sua efetivação. Como visto, a tensão relacionada ao direito à saúde, incide na dicotomia existente entre os direitos garantidos pela lei e os conflitos implícitos à sua concretização no cotidiano dos indivíduos (Asensi, 2010). 


\section{CONSIDERAÇÕES FINAIS}

O estudo desvelou o sentido do tratamento de tuberculose para os contatos dos portadores de tuberculose, constatando que o doente reconhece a necessidade do tratamento correto e completo para chegar à cura. Entretanto, ressalta-se que muitas vezes os pacientes não conseguem prosseguir com o tratamento pelo fato dele modificar a vida do paciente e sua relação social. Considerando que a tuberculose acomete principalmente pessoas desfavorecidas economicamente, o tratamento longo e padronizado pode interferir na rotina de trabalho do indivíduo, acarretando a interrupção do tratamento para a manutenção de sua fonte de renda.

A descontinuidade do tratamento se relaciona com os dois sentidos políticos de liberdade, o negativo e o positivo. Enquanto no primeiro sentido a pessoa é comsiderada livre na medida em que nenhuma pessoa ou grupo interfere em suas ações; no sentido positivo, a liberdade é compreendida como a capacidade de autodeterminação do indivíduo, por meio da autonomia da vontade (Berlin, 2002).

Observa-se por meio das entrevistas, que a decisão de não prosseguir com o tratamento ocasiona resistência medicamentosa e recidiva da doença, aumentando o tempo e o custo do tratamento. Além disso, o abandono de tratamento centra-se no fato de que, o portador de tuberculose que não adere à terapêutica, continua doentee permanece como fonte de contágio. Tendo em vista as implicações decorrentes da recusa do tratamento, destaca-se o papel do Estado, em garantir que o indivíduo ou a coletividade fiquem o menos possível expostos ao risco. Governar a segurança implica proteger o interesse coletivo contra os interesses individuais (Foucault, 2008b).

A recusa do tratamento da tuberculose revela o desejo do indivíduo ser senhor de si próprio e a sua autonomia (sentido positivo). No entanto, enquanto a recusa do tratamento para doenças não infecciosas implica em riscos apenas individuais, a recusa do tratamento da tuberculose traz consequências mais amplas, considerando que a tuberculose pulmonar é uma doença transmissível por via aérea e a pessoa quando não adere ao tratamento pode transmiti-la a seus contatos colocando em risco a saúde do outro.

Considerando a diversidade de percepções sobre como melhor viver e diferentes estilos de comportamento que os indivíduos podem livremente escolher, o Estado brasileiro em caso de descontinuidade do tratamento da tuberculose, assume a concepção negativa da liberdade, interferindo na autonomia do indivíduo, tendo em vista que sua escolha pode representar riscos para a saúde de outras 
pessoas. Sendo necessárias intervenções públicas visando a garantia da saúde da população, de modo a atender às demandas sociais.

O tratamento da tuberculose no Brasil é ofertado exclusivamente no setor público, de acordo com as normas e protocolos de tratamento vigentes e recomendados pelo Ministério da Saúde. A análise das entrevistas mostra que o controle da venda de medicamentos pode ter várias interfaces, pois pode significar uma ação positiva do Estado para contribuir com a adesão do doente ao tratamento, mas também evidencia a vigilância do Estado, em termos de monitoramento, controlando os portadores de tuberculose da possível descontinuidade do tratamento. Desta forma, mesmo que o tratamento seja gratuito, os custos psicológicos, sociais e econômicos ocorridos com a ruptura das relações dos indivíduos devem ser levados em consideração pelos profissionais.

No Brasil, após realizadas todas as medidas para adesão do paciente, medidas judiciais podem entrar em ação em casos de descontinuidade de tratamento que ameacem à saúde da população como a internação compulsória. Essa estratégia remete às primeiras medidas de controle da enfermidade, em que a pessoa acometida pela tuberculose era isolada socialmente, terapêutica que contribuiu de forma relevante para a estigmatização dos doentes. Assim, a liberdade individual de escolha em relação ao tratamento ofertado perpassa por valores enraizados socialmente, em que o indivíduo não é visto como sujeito de ações, mas como transgressor de normas e fonte de infecção. Longe de propor uma solução, esse artigo aponta a tensão inerente entre a liberdade individual e a saúde coletiva, a partir do caso estudado, e a necessidade de um debate público mais abrangente capaz de situar o problema e as possíveis (ou contingentes) soluções no âmbito das escolhas socialmente desejáveis e não apenas limitadas aos tomadores de decisão (gestores) em saúde.

\section{REFERÊNCIAS}

Alves, P. C., Rabelo, M. C. (1999). Significação e metáforas na experiência da enfermidade. Em M. C. M. Rabelo, P. C. B. Alves, I. M. A. Souza (org.), Experiência de Doença e Narrativa (pp. 171-185). Rio de Janeiro, Brasil: Fiocruz.

Asensi, F. D. (2010). Judicialização ou juridicização? As instituições jurídicas e suas estratégias na saúde. Physis: Revista de Saúde Coletiva, (20), pp. 33-55.

Barreira, I. A. (1992). A enfermeira Ananéri no "País do futuro": a aventura da luta contra a tuberculose [tese de doutorado]. Rio de Janeiro, Brasil: Universidade Federal do Rio de Janeiro. 
Berlin, I. (2002). Dois conceitos de liberdade. Em I. Berlin, H. Hardy, R. Hausheer (org.), Estudos sobre a humanidade: uma antologia de ensaios (pp. 226-272). São Paulo, Brasil: Companhia das Letras.

Bertolozzi, M.R. (1998). Adesão ao Programa de Controle da Tuberculose no Distrito Sanitário do Butantã [tese de doutorado]. São Paulo, Brasil: Universidade de São Paulo.

Campos, G. W. S. (2003). Saúde Paidéia. São Paulo, Brasil: Hucitec.

Chizzotti, A. (2006). Pesquisa qualitativa em ciências humanas e sociais. Petrópolis, Brasil: Vozes.

Departamento de Informática do Sistema Único de Saúde (DATASUS). (2014). Informações epidemiológicas e morbidade. Disponível em http://www.datasus.gov.br

Foucault, M. (2005). Em defesa da sociedade. São Paulo, Brasil: Martins Fontes.

Foucault, M. (2008a). Segurança, território, população. São Paulo, Brasil: Martins Fontes.

Foucault, M. (2008b). Nascimento da biopolítica. São Paulo, Brasil: Martins Fontes.

Foucault, M. (2013). Microfísica do poder (26 ed.). São Paulo, Brasil: Graal.

Fujiwara P. I., Larkin C., Frieden T. R. (1997). Directly observed therapy in New York City. History, implementation, results, and challenges. Clinics in Chest Medicine, (18), pp. 135-148.

Gil, A. C. (1999). Métodos e técnicas de pesquisa social (5 ed.). São Paulo, Brasil: Atlas.

Herzlich, C. (2005). A problemática da representação social e sua utilidade no campo da doença. Physis: Revista de Saúde Coletiva, (15), pp. 57-70.

Instituto Brasileiro de Geografia e Estatística (IBGE). (2013). Estimativas populacionais para os municípios brasileiros em 01.07.2013. Disponível em https://ww2.ibge.gov.br/home/estatistica/populacao/estimativa2013/default.shtm

Instituto de Pesquisa Econômica Aplicada (IPEA). (2011). Epidemiologia das doenças negligenciadas no Brasil e gastos federais com Medicamentos. Brasília, Brasil: IPEA.

Júnior, G. M. S., Santos, D. O., Gibaut, M. A. M., Bispo, T. C. F. (2016). Tuberculose: adesão ao tratamento e os fatores que desencadeiam em abandono. Revista Enfermagem Contemporânea, 5(2), pp. 284-292

Larroque, M. M., Santos, B. M. O. S. (2015). Promoção da saúde e tuberculose. Arquivos de Ciências da Saúde UNIPAR, 19(3), pp. 221-228.

Lopes, A. M. P. (2012). Saúde no processo de democratização brasileiro: promoção da saúde, biopolíticas e práticas de si na constituição de sujeitos da saúde [tese de doutorado]. Florianópolis, Brasil: Universidade Federal de Santa Catarina.

Marconi, M. A., Lakatos, E. M. (2003). Fundamentos de metodologia científica (4 ed.). São Paulo, Brasil: Atlas. 
Ministério da Saúde. (2011). Manual de recomendações para o controle da tuberculose no Brasil. Brasília, Brasil: Ministério da Saúde, Secretaria de Vigilância em Saúde.

Ministério da Saúde. (2012). Boletim Epidemiológico. Brasília, Brasil: Ministério da Saúde, Secretaria de Vigilância em Saúde.

Nascimento, E. C. (2009). Vale do Jequitinhonha: Entre a carência social e a riqueza cultural. Revista Contemporâneos, (4). Disponível em https://www.revistacontemporaneos.com.br/n4/pdf/jequiti.pdf

Oliveira H. B., Moreira Filho D. C. (2000). Abandono de tratamento e recidiva da tuberculose. Revista de Saúde Pública, 34(5), pp. 437-443.

Perini, E. (1998). O abandono do tratamento da tuberculose: transgredindo regras, banalizando conceitos [tese de doutorado]. Belo Horizonte, Brasil: Universidade Federal de Minas Gerais.

Pessoto, U. C., Ribeiro, E. A. W., Guimarães, R. B. (2015). O papel do Estado nas políticas públicas de saúde: um panorama sobre o debate do conceito de Estado e o caso brasileiro. Saúde Social, 24(1), pp. 9-22.

Ramos, C. A. (2011). O modelo liberal e republicano de liberdade: uma escolha disjuntiva? Trans/Form/Ação, 34(1), pp. 43-66.

Rastogi, N., David, H. L. (1993). Mode of action of antituberculous drugs and mechanisms of drug resistance in Mycobacterium tuberculosis. Research in Microbiology, 144(2), pp. 133-143.

Reiners, A. A. O., Azevedo, R. C. S., Vieira, M. A., Arruda, A. L. G. (2008). Produção bibliográfica sobre adesão/não-adesão de pessoas ao tratamento de saúde. Revista Ciência e Saúde Coletiva, 13(Suppl. 2), pp. 2299-2306.

Ribas, T. F. (2017). Práticas de liberdade em Foucault. Doispontos, 14(1), pp. 181-197.

Rosen, G. (1994). Uma história da saúde pública. Rio de Janeiro, Brasil: Associação Brasileira de Pós-Graduação em Saúde Coletiva.

Ruffino-Netto A. (1991). Tuberculose. Revista do Hospital das Clínicas da Faculdade de Medicina, (24), pp. 225-240.

Santos, M. S. A. (2012). Trajetória sociopolítica das mulheres inseridas na política partidária em Araçuaí - MG: conquistas e desafios. Araçuaí, Brasil: Instituto de Ciências Humanas e Sociais da Universidade Federal de Ouro Preto.

Sbarbaro, J. (1997). Directly observed therapy - Who is responsible? Clinics in Chest Medicine, (18), pp. 131-133.

Silva, R. (2008). Liberdade e lei no neo-republicanismo de Skinner e Pettit. Lua Nova, (74), pp. 151-194.

Silva, A. C. A. (2009). Dores do corpo e dores da alma: o estigma da tuberculose entre homens e mulheres acometidos [tese de doutorado]. Campinas, Brasil: Universidade Estadual de Campinas. 
Soares, J. A. S., Alencar, L. D., Cavalcante, L. P. S., Alencar, L. D. (2014). Impactos da urbanização desordenada na saúde pública: leptospirose e infraestrutura urbana. Polêm!ca, 13(1). Disponível em https://www.e-publicacoes.uerj.br/index.php/polemica/article/view/9632/7591

Terra, M. F., Bertolozzi, R. (2008). Tratamento diretamente supervisionado (DOTS) contribui para a adesão ao tratamento da tuberculose? Revista Latino-am Enfermagem, 16(4). Disponível em http://www.scielo.br/pdf/rlae/v16n4/pt_02.pdf

Triviños, A. N. S. (1990). Introdução à pesquisa em ciências sociais: a pesquisa qualitativa em educação. São Paulo, Brasil: Atlas.

Vendramini, S. H. F. (2001). O tratamento supervisionado no controle da tuberculose em Ribeirão Preto sob a percepção do doente [dissertação de mestrado]. Ribeirão Preto, Brasil: Escola de Enfermagem de Ribeirão Preto.

Vendramini, S. H. F., Villa, T. C. S., Palha, P. F., Monroe, A. A. (2002). Tratamento supervisionado no controle da tuberculose em uma unidade de saúde de Ribeirão Preto: a percepção do doente. Boletim de Pneumologia Sanitária, 10(1), pp. 5-12. 